\title{
PROMESSAS E DESAFIOS DOS AVANÇOS BIOTECNOLÓGICOS
}

\author{
Promises and challenges of biotechnological advances
}

\begin{abstract}
Humberto Maciel França Madeira
Engenheiro Agrônomo. Ph.D. em Ciência Animal. Diretor do Curso de Biotecnologia da Pontifícia Universidade Católica do Paraná. Curitiba, PR - Brasil, e-mail: h.madeira@pucpr.br
\end{abstract}

\section{Resumo}

A velocidade dos avanços biotecnológicos, associada à complexidade do tema, sofre efeito de freios sociais que impedem sua adoção mais prontamente, incluindo componentes éticos e de percepção de riscos e benefícios. Por outro lado, o potencial de geração de riqueza pelo desenvolvimento da biotecnologia pressiona as economias de diversos países a tornando área prioritária de investimento. A adoção segura da biotecnologia passa pelo equacionamento dessas forças aparentemente antagônicas, pela utilização de um enfoque multidisciplinar que envolva consolidação de governança na área da bioética, comunicação culturalmente eficaz e formação de recursos humanos qualificados.

Palavras-chave: Biotecnologia; Percepção de risco; Bioética.

\begin{abstract}
The pace at which biotechnology advances along with the complexity of the field are affected by social brakes that prevent its prompt adoption, including ethical and perception of risk/benefit aspects. On the other hand, the potential for wealth generation from biotechnology pull many country economies toward selecting it as an area of investment priority. The safe adoption of biotechnology is dependent upon solving the apparent antagonism between such forces. A multidisciplinary approach comprising of bioethics governance, culturally efficient communication and training of qualified human resources is needed.
\end{abstract}

Keywords: Biotechnology; Risk perception; Bioethics. 


\section{INTRODUÇÃO}

O impacto dos avanços biotecnológicos se faz percebido na sociedade contemporânea nas mais diversas formas. Do desenvolvimento de drogas mais eficazes à clonagem de animais, da produção de biocompostos por meio de engenharia genética às promessas do uso de células-tronco, a moderna biotecnologia tem suscitado sentimentos e percepções antagônicos como esperança e temor, afirmação e incerteza, promessa e desafio. A despeito da pressão da economia de mercado, dirigida por grandes corporações, a percepção pública e o aval da sociedade por meio dos princípios éticos vigentes têm papel chave na implantação e aquisição dos avanços biotecnológicos. Este texto traz algumas considerações sobre o potencial de contribuição da biotecnologia, bem como sobre o papel da percepção de risco e benefício sobre a aceitação das biotecnologias.

\section{DESENVOLVIMENTO}

\section{Cenário}

Acontecimentos recentes no cenário local e nacional despertaram a motivação para apresentação do tema. Em âmbito local, destaca-se a oferta do curso de graduação (bacharelado) em Biotecnologia pela Pontifícia Universidade Católica do Paraná, com atividades acadêmicas iniciadas em fevereiro de 2008. Por ser o primeiro curso dessa natureza ofertado no país por instituição de ensino superior comunitária e confessional, não será ousado sugerir que a instituição deva estar preparada para se posicionar quanto a questionamentos associados ao tema a serem feitos pela comunidade. De fato, nesse sentido, já colocando em foco a questão da percepção pública, destaca-se o impacto de recente entrevista do bispo regente do Tribunal da Penitenciaria Apostólica, D. Gianfranco Girotti, ao jornalista Nicola Gori, do jornal oficial do Vaticano L'Osservatore Romano (GORI, 2008). Quando indagado com a pergunta "Quais são, para o Sr., os novos pecados?", respondeu:

Vi sono varie aree all'interno delle quali oggi cogliamo atteggiamentipeccaminosi nei riguardi dei diritti individuali e sociali. Innanzitutto l'area della bioetica, all'interno della quale non possiamo non denunciare alcune violazioni dei fondamentali diritti della natura umana, attraverso esperimenti, manipolazioni genetiche, i cui esiti è difficile intravedere e tenere sotto controllo. Un'altra area, propriamente sociale, èl'area della droga, attraverso cui siindebolisce la psiche e si oscura l'intelligenza, lasciando molti giovani al di fuori del circuito ecclesiale. Ancora: l'area delle sperequazioni sociali ed economiche: nelle quali i più poveri diventano semprepiù poveri ei ricchi semprepiù ricchi, alimentando una insostenibileingiustizia sociale, l'area dell'ecologia, che riveste oggi un rilevante interesse.

O impacto dessa resposta foi sentido em todo o mundo. A parte inicial da opinião do bispo, traduzida livremente para "Há muitas áreas dentro das quais, hoje em dia, vemos atitudes pecaminosas a respeito dos direitos individuais e sociais. Acima de tudo na área da bioética, dentro da qual não podemos deixar de denunciar algumas violações dos direitos fundamentais da natureza humana, através de experiências, manipulações genéticas, cujo êxito é difícil vislumbrar e ter sob controle," causou especial agitação no meio científico e na opinião pública em geral. Agências noticiosas veicularam citações à entrevista, generalizando a manipulação genética como pecado, ao dar manchetes como "Manipulação genética e poluição são pecados modernos, diz Vaticano" (MARQUES et al., 2008). De fato, a resposta não incluiu em si, como pecado, toda e qualquer manipulação genética, mas aquelas que possam violar direitos fundamentais da pessoa humana e a santidade da vida. Sendo assim, a resposta se coaduna com a posição tradicional do Vaticano, conforme descrita na Instrução "Donum Vitae" e na Carta Encíclica "Evangelium Vitae" (CONGREGATION FOR THE DOCTRINE OF THE FAITH, 1987; JOÃO PAULO II, 1995). Mas não será especular dizer que para muitos, da população em geral, o entendimento que ficou é de que a manipulação genética, qualquer que seja, é condenada pelo 
Vaticano, graças à interpretação equivocada da veiculação sintética da entrevista. Como consequência desse fato, os próprios bacharelandos em Biotecnologia da PUCPR, também eles próprios questionados por familiares e pessoas do seu círculo de relacionamentos, passaram a questionar a Instituição sobre o tema. $\mathrm{O}$ autor do presente artigo já teve a oportunidade de, publicamente, dialogar sobre o tema com os alunos, mas com o vir a lume deste artigo espera-se que esses esclarecimentos tenham maior alcance.

Outro acontecimento recente de grande impacto na opinião pública, no âmbito nacional, se deu dias antes. O dia cinco de março de dois mil e oito foi marcado pela suspensão do julgamento, pelo Supremo Tribunal Federal, da Ação Direta de Inconstitucionalidade, requerido pelo Procurador-Geral da República, em nome dos interessados Conecta Direitos Humanos, Centro de Direitos Humanos $(\mathrm{CDH})$, Movimento em Prol da Vida - MOVITAE, ANIS - Instituto de Bioética, Direitos Humanos e Gênero, e a CNBB - Confederação Nacional dos Bispos do Brasil (BRASIL, 2005b). Tal ação teve como alvo o artigo 5 da Lei Federal, no 11.105 ("Lei da Biossegurança"), de 24 de março de 2005, que trata da utilização de células-tronco embrionárias, assim integralmente redigido:

Art. $5^{\circ}$ É permitida, para fins de pesquisa e terapia, a utilização de células-tronco embrionárias obtidas de embriões humanos produzidos por fertilização in vitro e não utilizados no respectivo procedimento, atendidas as seguintes condições:

I-sejam embriões inviáveis; ou

II - sejam embriões congelados há 3 (três) anos ou mais, na data da publicação desta Lei, ou que, já congelados na data da publicação desta Lei, depois de completarem 3 (três) anos, contados a partir da data de congelamento.

$\int 1^{\circ}$ Em qualquer caso, é necessário o consentimento dos genitores.

\2 Instituições de pesquisa e serviços de saúde que realizem pesquisa ou terapia com célulastronco embrionárias humanas deverão submeter seus projetos à apreciação e aprovação dos respectivos comitês de ética em pesquisa.

$\int 3^{\circ}$ É vedada a comercialização do material biológico a que se refere este artigo e sua prática implica o crime tipificado no art. 15 daLeino 9.434, de 4 de fevereiro de 1997 (BRASIL, 2005a).

Desde aquela data, quando o julgamento foi suspenso pelo pedido de vistas do Ministro Carlos Alberto Menezes Direito, o país voltou a debater intensamente a questão, e grupos organizados em defesa de portadores de doenças degenerativas têm recebido destaque da mídia televisiva, por meio de suas manifestações em Brasília, pelo voto contrário à ADIN e seu consequente arquivamento, para que possam ser novamente autorizadas as pesquisas com células-tronco, conforme descritas na Lei de Biossegurança. Pesquisas de opinião, divulgadas recentemente, apontam que a maioria da população brasileira é a favor das pesquisas com células-tronco embrionárias para descobrir tratamentos para doenças graves, segundo levantamento feito pelo Ibope, com amostragem nacional, entre os dias 24 e 29 de janeiro (IWASSO, 2008). O conjunto de pessoas que concordam totalmente com a liberação é de $75 \%$. Já 20\% afirma concordar parcialmente. A afirmação formulada aos entrevistados foi: "Apoiar as pesquisas com células-troco embrionárias para o tratamento e recuperação de pessoas com doenças graves é uma atitude em defesa da vida". Cabe ressaltar que o próprio subtítulo da manchete enfatizou que esse foi um dos raros resultados de pesquisa que a população discorda da Igreja Católica.

Do cerne da questão ética, no entanto, tem se passado ao largo, que trata da dignidade dos embriões, que mesmo congelados podem manter-se viáveis. Ou ainda, a própria questão de geração de embriões supranumerários nos procedimentos, visando fertilização in vitro, embriões cuja maioria terá como destino o congelamento, jamais fez parte da pauta de dicussão da sociedade brasileira, deixando um vazio ético e jurídico que grandemente dificulta as dicussões sobre o uso de células-trono embrionárias. De fato, considerando a visão da Igreja Católica, que questiona a ética da produção de 
embriões, cujo destino certo será o congelamento, a discussão sobre o uso de células-tronco que destroem o embrião passa a levantar o difícil dilema ético: "Pode-se fazer o bem (eventual benefício do uso das células-tronco) a partir de um mal (embriões congelados) anteriormente cometido?" Ou ainda, "fazer o bem a partir desse mal cometido não retroalimenta o mal?" Pode-se apenas esperar que essa discussão permeie a sociedade e produza marcos legais que venham a reger os procedimentos de fertilização in vitro, e, como consequência, trazer encadeamento lógico às discussões éticas que envolvem a utilização dos embriões congelados conforme o que dispõe a Lei 11.105.

\section{A percepção pública e a adoção de biotecnologias}

O cenário anteriormente apresentado destaca aspectos da percepção pública de biotecnologias, podendo ser identificados componentes meramente utilitaristas na decisão ética pelo uso das céulastronco, alijando os princípios da autônima e da justiça da discussão. Qual o caminho a ser adotado por uma nação, para que de fato ela assuma uma postura ética devidamente debatida, madura no que se refere ao uso de novas biotecnologias? Argumenta-se aqui que a percepção pública de riscos e benefícios tem papel primordial, para que o tema possa evoluir e amadurecer. O entendimento da dinâmica da percepção pública das tecnologias tem sido estudado cientificamente por psicólogos e merece destaque a seguir.

Um detalhado estudo recente sobre a aceitação da nanotecnologia coletou dados de um universo de 1.862 indivíduos norte-americanos amostrados entre 40.000 recrutados, cuja distribuição demográfica refletia a dos Estados Unidos da América como um todo (KAHAN et al., 2008). As conclusões do trabalho possivelmente poderiam ser aplicadas a outras tecnologias: quando a população em geral avalia argumentos conflitantes sobre os benefícios e riscos potenciais de uma nova tecnologia, as pessoas terão a tendência de concordar com os experts naquela tecnologia cujos valores são os mais próximos dos seus, independentemente da posição que esse expert assuma. De fato, duas hipóteses iniciais foram testadas: a de "Iluminismo Racional" e a de "Cognição Cultural".

Como parte do estudo, por meio de um questionário, os participantes leram argumentos antagônicos que foram aleatoriamente atribuídos a experts fictícios de grandes universidades para que formassem sua opinião sobre nanotecnologia - uma tecnologia de ponta sobre a qual muito pouco é de conhecimento do público em geral. Como a maioria das pessoas não têm tempo nem conhecimento necessário para compreender informação científica sobre assuntos complexos e novos, eles naturalmente ficam na dependência da opinião de experts em quem eles confiam, para que então determinem em qual informação acreditam. Os indivíduos têm a tendência de confiar naquelas pessoas com as quais compartilham suas perspectivas culturais.

A hipótese de iluminismo racional estabelece que membros da sociedade passarão a ter disposição favorável a nanotecnologia conforme informações precisas e não-tendenciosas sobre ela se disseminarem. O fenômeno de cognição cultural se refere à tendência das pessoas em encaixar suas crenças sobre riscos e benefícios de uma atividade potencialmente perigosa dentro de suas percepções culturais a respeito dessas atividades (DiMAGGIO, 1997). Basicamente, é muito mais simples, sob o ponto de vista psicológico, acreditar que um comportamento considerado por ela como nobre ser também socialmente benéfico e vice-versa: um comportamento que ela considera imoral ser consequentemente perigoso. Essa dinâmica já se mostrou responsável por levar pessoas de diferentes perspectivas culturais a polarizar, conforme elas reagem a informações sobre diferentes riscos - de aquecimento global a terrorismo doméstico (CULTURAL COGNITION PROJECT, 2007).

As características que mais influenciaram o estudo foram os valores individuais básicos dos sujeitos da pesquisa, também chamada de orientação cultural. Estudos de cognição cultural sobre riscos caracterizam a sociedade, com respeito a preferências de como elas devem ser organizadas, em duas dimensões bastante distintas: o "individualismo/comunitarismo" ou "hierarquia/igualitarismo". Pessoas que possuem visões de mundo individualistas tendem a desconsiderar riscos tecnológicos e ambientais porque percebem (subconscientemente) que dar crédito a esses riscos justificaria a criação de restrições de mercado e outras restrições à liberdade individual. Indivíduos que possuem preferências hierárquicas reagem de maneira similar porque associam afirmações sobre riscos ambientais e tecnológicos como

Rev. Acad., Ciênc. Agrár. Ambient., Curitiba, v. 6, n. 2, p. 309-316, abr./jun. 2008 
desafios às elites sociais e governamentais. Pessoas que são relativamente igualitárias, em contraste, tendem a considerar os argumentos de risco da tecnologia porque isso é consonante com sua desconsideração pelo comércio e indústria como atividades que geram desigualdade. Os de disposição comunitária, também, são relativamente sensíveis aos riscos, porque têm a visão de que negócios e indústria são símbolos de busca desenfreada pelo interesse pessoal. Tais tendências são particularmente pronunciadas entre pessoas que possuem combinação desses valores (hierárquicas e individualistas, igualitárias e comunitárias) (KAHAN et al., 2008).

Esse estudo identifica algumas das barreiras que os formadores de políticas enfrentam ao desenvolver uma estratégia abrangente para proporcionar aos cidadãos acesso à informação tecnológica. Ele destaca a urgência em comunicar com o público a respeito da tecnologia, enquanto ela ainda está em estágio inicial de comercialização. O estudo enfatiza também a necessidade de fazer a informação chegar a pessoas em que o público confia, a fontes de opinião vistas com credibilidade para o público.

Para se ter uma idéia da dimensão e complexidade dos temas a serem debatidos e analisados pela comunidade, Simon; Kotler (2004) sumarizaram os benefícios e riscos da biociência (Tabela 1). Considerando a complexidade dos temas envolvidos, contrapondo-se a velocidade com que essas tecnologias tem chegado ao mercado, pode-se questionar que os freios socias que possam impedir a adoção das biotecnologias acabam por ser seletivos àquelas cuja percepção de risco sejam maiores ou àquelas que tenham impacto mais direto sobre a pessoa humana.

TABELA 1 - Benefícios e riscos da biociência

Table 1 - Benefits and risks of bioscience

\begin{tabular}{|c|c|c|c|}
\hline Setor Industrial & Tecnologia & Benefício & Barreira/Risco \\
\hline Diagnóstico humano & $\begin{array}{l}\text { Triagem genética } \\
\text { (chips de DNA) }\end{array}$ & $\begin{array}{l}\text { Prevenção, tratamento } \\
\text { direcionado }\end{array}$ & $\begin{array}{l}\text { Discriminação por seguradoras/ } \\
\text { empregadores }\end{array}$ \\
\hline \multirow[t]{2}{*}{ Terapia humana } & $\begin{array}{l}\text { Terapia genética } \\
\text { somática }\end{array}$ & $\begin{array}{l}\text { Maior eficácia e } \\
\text { tolerância }\end{array}$ & $\begin{array}{l}\text { Risco do vetor viral na aplicação } \\
\text { da droga }\end{array}$ \\
\hline & $\begin{array}{l}\text { Terapia genética } \\
\text { germinativa }\end{array}$ & $\begin{array}{l}\text { Erradicação dos } \\
\text { caracterres das doenças }\end{array}$ & Eugenia parental \\
\hline \multirow[t]{3}{*}{ Computação } & Bioinformática & $\begin{array}{l}\text { Banco de dados genéticos } \\
\text { globais }\end{array}$ & Obtenção de patentes, privacidade \\
\hline & Biometria & $\begin{array}{l}\text { Viagens, comércio } \\
\text { eletrônico }\end{array}$ & Privacidade \\
\hline & $\begin{array}{l}\text { Computadores } \\
\text { biomiméticos }\end{array}$ & Pesquisa em proteômica & Custo, complexidade \\
\hline \multirow[t]{2}{*}{ Agrobiotecnologia } & $\begin{array}{l}\text { Agroprodução } \\
\text { de moléculas }\end{array}$ & $\begin{array}{l}\text { Drogas, alimentos } \\
\text { medicinais }\end{array}$ & Impactos ecológicos imprevisíveis \\
\hline & Animais transgênicos & Substituição de órgãos & Transmissão de vírus \\
\hline Materiais & Nanotecnologia & $\begin{array}{l}\text { Materiais "inteligentes" } \\
\text { (automontagens, } \\
\text { memória) }\end{array}$ & $\begin{array}{l}\text { Custo de desenvolvimento, } \\
\text { complexidade }\end{array}$ \\
\hline Energia & Biocombustíveis & $\begin{array}{l}\text { Redução da poluição, } \\
\text { recursos renováveis }\end{array}$ & $\begin{array}{l}\text { Custo de desenvolvimento/ } \\
\text { produção }\end{array}$ \\
\hline Meio ambiente & Biorremediação & Eficácia & Impactos ecológicos imprevisíveis \\
\hline
\end{tabular}

Fonte: Simon e Kotler (2004). 
Preocupados com a dificuldade e morosidade dos estudos éticos quando comparados à velocidade dos avanços científicos, uma iniciativa que merece menção é a do Institute on Biotechnology and the Human Future, mantido pela Chicago-Kent College of Law e o Illinois Institute of Technology. Ao considerar o papel dos diversos atores do processo, incluindo os cientistas, o setor privado, o governo e seus legisladores, a proposta de um sistema de governança multilateral e multidisciplinar é lançada (ANNAS, 2008):

Albert Einstein fez a convincente observação de que "imaginação é mais importante que o conhecimento". Ele poderia ter ido além. Imaginação moral é mais importante do que imaginação científica. O desafio a ser conquistado pela ciência no início do século XXI éo desenvolvimento de um sistema de governança bioética global que possa contribuir para que se garanta que a tecnologia biomédica promova a vida humana, sem causar prejuízo a ela ou acabe com ela. Paradoxalmente, a agenda de pesquisa biotecnológica global está olhando para trás e para frente ao mesmo tempo. Olhando para trás, estamos tentando reagir às ameaças de pandemias globais, bioterrorismo e guerra biológica. Olhando para frente, estamos nos esforçando para utilizar novas tecnologias biomédicas não só para curar ou prevenir doenças, mas também para modificar fisicamente as pessoas de maneira que poderia mudar nosso conceito de humanidade. Até o momento o mundo está levando mais seriamente em conta a governança de tecnologias vistas a partir do olhar para trás do que aquelas vistas no futuro. Isto provavelmente é resultado do fato de que o mundo teve muitas experiências com pandemias e guerras, porque o medo é o elemento motivador mais forte, bem como porque todos podemos imaginar o que o bioterrorismo pode causar com um novo vírus. Nós precisamos exercitar nossa imaginação moral para criar uma estrutura que possa agir como uma consciência virtual global para a comunidade científica envolvida em biotecnologias que alteram as espécies e biotecnologias que levem espécies à extinção. Essa estrutura supervisionadora tem que ser global e deve incluir representantes de governos, indústria, organizações não-governamentais e diretamente da população. Esse grupo teria como tarefa articular regras substantivas de pesquisa de âmbito global (utilizando como base documentos existentes sobre direitos humanos, como o Código de Nuremberg, the Covenant on Civil and Political Rights, a Convenção Européia de Direitos Humanos e Biomedicina), estudando e aprovando (ou rejeitando) todos os projetos envolvendo alterações de espécies ou procedimentos potencialmente perigosos à sobrevivência de espécies, além de monitorar esses experimentos durante seu desenvolvimento. O fato de podermos imaginar os horrores de uma pandemia de gripe aviária ou de um ataque bioterrorista, mas não o de imaginar formas de desenvolver e exercitar uma "consciência de espécie" é um atributo potencialmente letal dos seres humanos da atualidade.

Dadas as diferenças culturais de cada país, mesmo em época de globalização, é premente a necessidade do amadurecimento das discussões éticas associadas à biotecnologia no Brasil, para que possamos ingressar no debate de uma governança global de maneira madura. A pressão de promessas que geram expectativas positivas exageradas sem comprovação, ou ainda dependentes de transporem obstáculos técnico-científicos consideráveis, aliadas ao fato da distância a ser vencida futuramente para que o acesso a biotecnologia atinja o nível assistencial, acabam por atropelar o debate numa sociedade imediatista como a brasileira.

\section{Potencial de contribuição das biotecnologias}

Ao lado dos potenciais benefícios da aplicação das diversas biotecnologias em áreas como saúde, meio-ambiente, indústria e agricultura (Tabela 1), como setor industrial propriamente dito, a biotecnologia é vista hoje como um dos principais geradores de riqueza (ALONSO, 2003). Em termos gerais, o biossetor estimadamente já responde por mais de um terço do PIB mundial. Somente nos EUA, a dimensão das indústrias envolvidas situava-se, em 2000, entre US $\$ 400$ bilhões no setor químico e US\$ 800 bilhões no setor agroindustrial e mais de US\$ 1 trilhão no ramo de biomateriais (OLIVER, 2000). 
A biotecnologia é uma área portadora de futuro por excelência, tendo sido escolhida como prioritária em programas estratégicos do Governo Federal por meio das Diretrizes de Política Industrial, Tecnológica e de Comércio Exterior - PITCE, (BRASIL, 2003). A PITCE elege duas grandes áreas de ação. Primeiro, são eleitas opções estratégicas que contemplam quatro programas setoriais. São destacados setores que contribuem, de maneira direta e indireta, para os déficits na balança comercial brasileira, por serem setores ligados à "nova economia": semicondutores e software. Já o setor de bens de capital foi eleito por impulsionar toda a cadeia industrial. O motivo específico da inlcusão dos fármacos não foi fundamentado. Segundo, a PITCE elege, em um único programa, segmentos tecnológicos "portadores de futuro": biotecnologia e nanotecnologia (CAMPANARIO et al., 2004). Recentemente, foi sancionado o decreto criando o Comitê Nacional de Biotecnologia e instituindo uma política específica para o setor. A nova política permitirá investimentos de $\mathrm{R} \$ 10$ bilhões nos próximos 10 anos, com recursos do Orçamento Geral da União e do BNDES.

No Paraná, estado com elevada participação do agronegócio em seu PIB, todas as seis regiões estudadas pelo Sistema Federação das Indústrias (FIEP) apresentam como setor portador de futuro o das agrobiotecnologias (OPTI/SENAI, 2005). Como um todo para o estado, os macro-setores de Biotecnologia, Indústria Alimentar e Energias Renováveis compõem os setores estratégicos listados.

\section{CONSIDERAÇÕES FINAIS}

A opção pela biotecnologia como área estratégica para o desenvolvimento está tomado pelas mais diferentes nações do planeta. O Brasil e o Estado do Paraná, dados sua biodiversidade e potencial de produção agrícola estão em posição privilegiada para ocupar papel de destaque nesse novo cenário. A formação de recursos humanos altamente qualificados torna-se fundamental para dar suporte às políticas estratégicas adotadas. A PUCPR, com a criação de seu curso de graduação em Biotecnologia, dá seu passo nesse sentido. Dada a complexidade do tema, os dilemas éticos envolvidos e a importância da percepção pública dos benefícios para sua aceitação, a difusão da biotecnologia toma contornos que vão além daqueles das áreas tradicionais da economia, desafiando a academia, o setor produtivo e demais atores sociais a um enfoque multidisciplinar para essa difusão, para que todo o potencial possa a vir ser usufruído.

\section{REFERÊNCIAS}

ALONSO, V. A hora da bioestratégia. HSM Management, v. 36, p. 64-69, 2003.

ANNAS, G. J. Governing biotechnology. Institute on Biotechnology and the Human Future. Chicago-Kent College of Law and Illinois Institute of Technology. 2005. Disponível em: http:// www.thehumanfuture.org/commentaries/general/general_commentary_annas01.htm >. Acesso em: 19 mar. 2008.

BRASIL. Governo Federal. Diretrizes de política industrial, tecnológica e de comércio exterior. 2003. 23 p. Disponível em: <http://www.abdi.com.br/abdi_redesign/publicacao/ download.wsp?tmp.arquivo=107>. Acesso em: 02 abr. 2008.

BRASIL. Lei n. 11.105, de 24 de março de 2005a. Disponível em: <http://www.planalto.gov.br/ ccivil_03/_Ato2004-2006/2005/Lei/L11105.htm>. Acesso em: 17 mar. 2008.

BRASIL. Supremo Tribunal Federal. Ação direta de inconstitucionalidade No. 3.510-0, tendo por alvo o artigo $5^{\circ}$ da Lei Federal no 11.105 (“Lei da Biossegurança"). de 24 de março de 2005b. Disponível em: <http://www.stf.gov.br/portal/peticaoInicial/verPeticaoInicial.asp?ba$\mathrm{se}=\mathrm{ADIN} \& \mathrm{~s} 1=3510 \&$ processo $=3510>$. Acesso em: 17/03/2008. 
CAMPANÁRIO, M. A. et al. Inovação tecnológica nas novas diretrizes da nova política industrial brasileira. Revista de Negócios, v. 9, n. 4, p. 195-206, 2004.

CONGREGATION FOR THE DOCTRINE OF THE FAITH. Instruction on Respect for Human Life in Its Origins and on the Dignity of Procreation "Donum Vitae" (22 Feb. 1987). Disponível em: <http: / / www.vatican.va/roman_curia/congregations/cfaith/documents / rc_con_cfaith_doc_19870222_respect-for-human-life_en.html>. Acesso em: 31 mar. 2008.

CULTURAL COGNITION PROJECT at Yale Law School. The second war of fact. 2007. Disponível em: <http://papers.ssrn.com/sol3/papers.cfm?abstract_id=1017189>. Acesso em: 21 mar. 2008.

DiMAGGIO, P. Culture and cognition. Annual Review of Sociology, v. 23, p. 263-287, 1997.

JOÃO PAULO II. Carta encíclica Evangelium vitae do Sumo Pontífice João Paulo II: aos bispos, aos presbíteros e diáconos, aos religiosos e religiosas, aos fiéis leigos e a todas as pessoas de boa vontade sobre o valor e a inviolabilidade da vida humana. São Paulo: Paulinas, 1995. (A voz do Papa ; 139)

IWASSO, S. 75\% dos brasileiros apóiam uso de células-tronco, diz Ibope. O Estado de São Paulo, São Paulo, Caderno Vida \& Saúde, A-16, 04 mar. 2008. Disponível em: <http:// www.estadao.com.br/geral/not_ger134474,0.htm>. Acesso em: 10 mar. 2008.

KAHAN, D. M., et al. The future of nanotechnology risk perceptions: an experimental investigation of two hypotheses. January 31, 2008. Disponível em: <http://ssrn.com/ abstract $=1089230>$. Acesso em: 14 mar. 2008.

MARQUES, G. et al. Manipulação genética e poluição são pecados modernos, diz Vaticano. O Estado de S. Paulo, São Paulo, Caderno Vida \& Saúde, A-16, 11 mar. 2008. Disponível em: <http:// www.estado.com.br/editorias/2008/03/11/ger-1.93.7.20080311.10.1.xml>. Acesso em: 11 mar. 2008.

GORI, N. L'Osservatore Romano. 9 Marzo 2008, p. 8. A colloquio con il reggente della Penitenzieria a conclusione del Corso per confessori:le nuove forme del peccato sociale. Disponível em: <http://www.crismon.it/forum/showthread.php?p=83222>. Acesso em: 28 mar. 2008.

OLIVER, R. The coming biotech age. New York: McGraw-Hill, 2000.

OPTI/SENAI - Setores portadores de futuro para o Estado do Paraná: horizonte de 2015. Relatório Técnico. Observatorio de Prospectiva Tecnológica Industrial. Curitiba: SENAI, 2005.

PORTER, A. et al. Technology futures analysis: toward integration of the field and new methods. Technological Forecasting \& Social Change, v. 71, n. 3, p. 287-303, 2004.

SIMON, F; KOTLER, P. A construção de biomarcas globais: levando a biotecnologia ao mercado. Porto Alegre: Bookman, 2004.

Recebido: 30/09/2007

Received: 09/30/2007

Aprovado: $31 / 10 / 2007$

Approved: 10/31/2007 